\title{
La opción por los pobres es opción por la justicia, y no es preferencial -Para un reencuadramiento teológico-sistemático de la opción por los pobres-
}

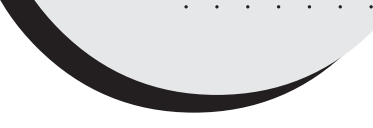

JosÉ María VIGIL*

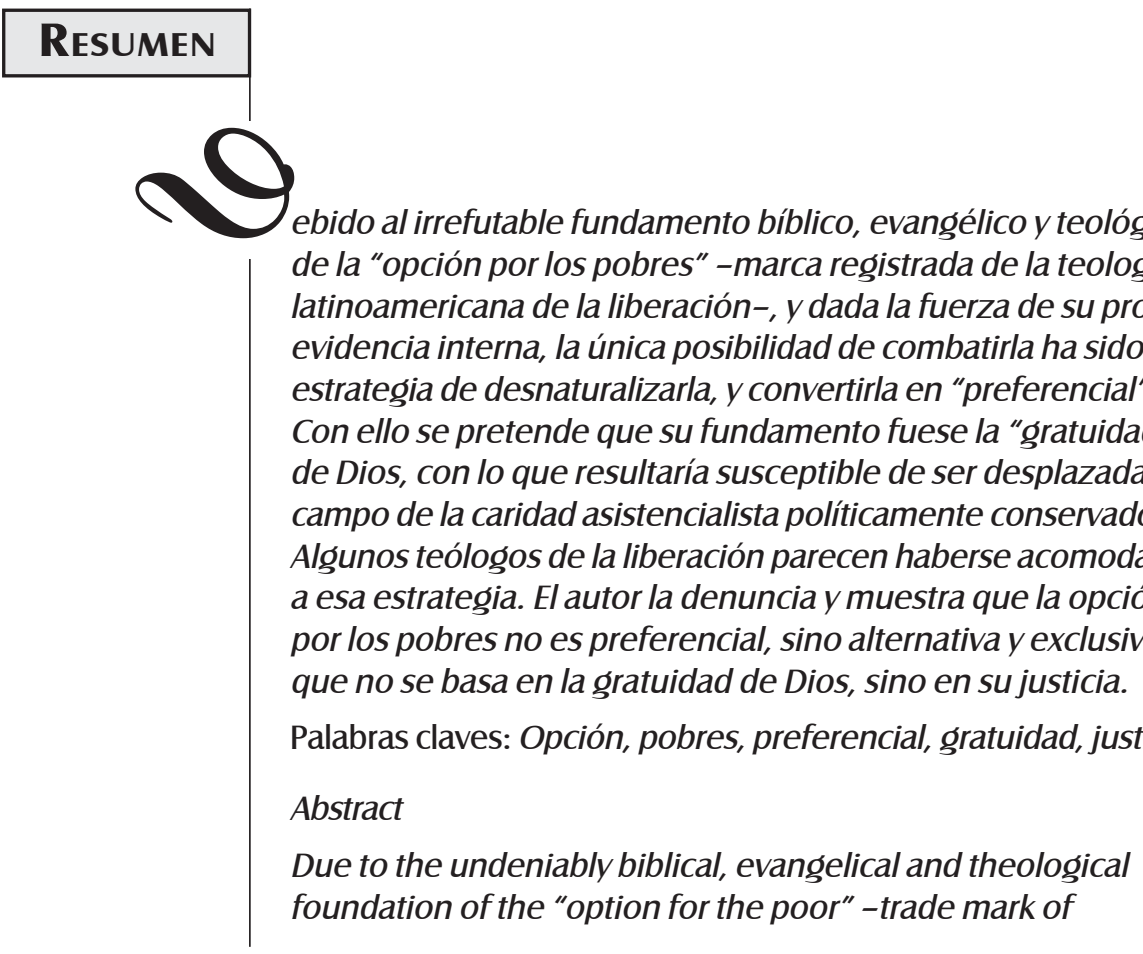

El autor estudió Teología en la Universidad Pontifica de Salamanca y en la Universidad Santo Tomás de Roma (Angelicum), y Psicología en las Universidades de Salamanca, Madrid y Managua. Fue profesor de teología en la Universidad de Salamanca, CRETA y en la Universidad Centroamericana, UCA de Managua. Ha sido director de la revista "Diakonía" del CICA, Centro Ignaciano de Centro América de la UCA de Managua y de la revista "Amanecer" del Centro Valdivieso de Managua. Ha publicado más de 200 artículos en revistas teológicas, 15 libros propios, y ha colaborado en varios otros libros colectivos. Correo electrónico: vigil@claret.org 
Latinamerican Liberation Theology-and given the strength of its own internal evidence, the only possibility of opposition to it has been the strategy of denaturalizing it and making it "preferential". With that its foundation is supposed to be God's gratuity, and so it could be relegated to the field of politically conservative assistential charity. Some liberation theologians seem to have accepted this strategy. The author denounces it and shows that the option for the poor is not preferential, but an exclusive alternative, and that it is founded not on God's gratuity but on his justice.

Key words: Option, poor, preferential, gratuity, justice.

\section{Situación de la Cuestión}

Siempre dijimos que la opción por los pobres se fundamenta en Dios mismo, en el ser de Dios, y que tiene por tanto naturaleza "teocéntrica"1 : de alguna manera, podemos decir que Dios mismo hace opción por los pobres ${ }^{2}$, Dios "es" opción por los pobres. Y era un consenso universalmente sentido que esta opción por los pobres se basaba precisamente en el amor-justicia del Dios bíblico y cristiano. ${ }^{3}$

Sin embargo, con el advenimiento de la "crisis de la teología de la liberación", algunos autores suavizaron su discurso sobre la opción por los pobres, prefiriendo abandonar la perspectiva del amor-justicia ${ }^{4}$ y sustituyéndola casi completamente por la de la "gratuidad" de Dios como fundamento de la opción por los pobres. En este nuevo planteamiento, Dios, simplemente "prefiere" a los pobres, tiene una "debilidad" misericordiosa,

1. "Digámoslo con claridad: la razón última de esa opción está en el Dios en quien creemos. (...) Se trata para el creyente de una opción teocéntrica, basada en Dios." (Gutiérrez, 1982: 53-54 y 1980: 261-262)

2. "Dios se revela como quien hace una opción por los pobres y esa opción es mediación esencial de su revelación" (Sobrino, 1993: 899).

3. A pesar de ser una obviedad, véase la tesis doctoral de Julio LOIS, Teología de la liberación: opción por los pobres (IEPALA, Madrid, 1986) que estudia la opción por los pobres en varios de los principales teólogos de la liberación del período clásico.

4. Un caso claro puede ser el de Gustavo Gutiérrez. En una ponencia pronunciada ante Ratzinger, afirma: "La temática de la pobreza y la marginación nos invita a hablar de justicia y a tener presente los deberes del cristiano al respecto. Así es en verdad, y ese enfoque es sin duda fecundo. Pero no hay que perder de vista lo que hace que la opción preferencial por los pobres sea una perspectiva tan central. En la raíz de esa

LA OPCIÓN POR LOS POBRES ES OPCIÓN POR LA JUSTICIA, Y NO ES PREFERENCIAL 
una "ternura" incontenible hacia ellos, y a este hecho no habría que buscarle muchas razones, precisamente por ser "gratuito".

La opción por los pobres resultaría ser una especie de "capricho" de Dios, hacia los "pequeños, los débiles, los insignificantes". De éstos sería de quienes hoy habría que hablar, y no ya de "Ios pobres" en el sentido fuerte ${ }^{5}$ del discurso clásico, que hoy estaría ya sobrepasado. La misma teología de la opción por los pobres debería desvincularse del tema fuerte de la justicia y ser adjudicada al tema suave de la gratuidad.

Mi tesis consiste en que este corrimiento o desplazamiento del acento desde la justicia hacia la gratuidad de Dios como fundamento de la opción por los pobres deteriora y finalmente malversa dicha opción -consciente o inconscientemente-, al convertirla en una simple "preferencia", un "amor preferencial", una simple prioridad de orden en la caridad" ${ }^{6}$, dejando de ser una verdadera "opción", una toma de partido disyuntiva y excluyente, como una opción fundamental, fundada para nosotros en la misma naturaleza de Dios.

No niego que tenga algún sentido afirmar que "Dios tiene una preferencia gratuita por los pequeños y los débiles"; pero sostengo que tal "preferencia" no puede ser identificada en un sentido preciso con la opción por los pobres, ni mucho menos puede ser puesta como fundamento de la misma. Confundir la opción por los pobres con esa "preferencia de Dios hacia los pequeños y los débiles", o con el llamado "amor preferencial por los pobres", y aplicarle el mismo nombre de opción por los pobres, es ser víctima de la confusión, o ceder ante la estrategia de quienes han intentado resignificar y ocupar el término opción por los pobres para despojarlo de su contenido propio. La opción por los pobres original y clásica latinoamerica-

opción está la gratuidad del amor de Dios. Este es el fundamento último de la preferencia." A partir de ese momento ya no vuelve a aparecer la palabra "justicia" en su disertación y toda la opción por los pobres gira en torno a la "gratuidad" (cfr. Varios, 1996: 111). No se trata de un texto aislado, sino, en mi modesta opinión, de una perspectiva suavizada común en la opción por los pobres de Gustavo hace más de una década (cfr. Gutiérrez, 1991: 303ss., 310).

5. Pobres que eran una realidad "colectiva, conflictiva y socialmente alternativa" (Boff, 1986: 17ss.).

6. Un amor igual para todos pero que empieza por los pobres y continúa por los ricos, sin hacer entre ellos ninguna diferencia; un "amor igualitario pero con un orden de prioridad", simplemente. 
na, la típica de la teología y la espiritualidad de la liberación, la opción por los pobres por la que murieron nuestros/as mártires, y que también nosotros consideramos "firme e irrevocable", es otra, y debe ser distinguida de cualquier sucedáneo. Una fidelidad valiente y lúcida debe rechazar consciente y explíticamente esta pretendida fundamentación de la opción por los pobres en la "gratuidad" de Dios. Es lo que quiero ayudar a aclarar. Para ello, nada mejor que tratar de reencuadrar sistemáticamente la naturaleza misma de la opción por los pobres.

\section{Primera tesis: En sentido estricto, Dios ama sin preferencias ni discriminaciones}

Afirmar lo contrario sería, en buena parte, un antropomorfismo.

Dios quiere y ama a todos/todas por igual, con un amor tan peculiar para cada persona, y a la vez tan infinito, que no hay posibilidad de cuantificaciones ni de comparaciones en ese amor. Toda persona puede sentirse amada infinitamente por Dios, y nadie debe sentirse "preferido" o discriminado positiva ni negativamente. No es posible hablar seriamente de "amores preferenciales" de parte de Dios respecto de algunos seres humanos frente a otros. Lo exige la suprema dignidad de la persona humana y la ecuanimidad infinita de Dios. Y todo lo que se aparte de aquí, sólo pueden ser formas inadecuadas de hablar, "demasiado humanas", antropomorfismos.

Dios no tiene parcializaciones, ni "acepción de personas". No las tiene por motivos de raza, ni de color, género o cultura... Dios ama a todas sus criaturas, con amor realmente "incuantificable e incomparable", en el que no caben preferencias ni discriminaciones.

\section{Segunda tesis: Dios opta por la justicia, no preferencialmente, sino alternativa y excluyentemente}

Hay sin embargo un campo en el que Dios es necesariamente radical e inflexiblemente parcial: el campo de la justicia. Ahí Dios se pone de parte de la justicia y en contra de la injusticia, sin la menor concesión, sin la menor "neutralidad", y sin simples "preferencias": Dios está contra la injusticia y se pone del lado de los "injusticiados" (las víctimas de la injusticia). Dios no

LA OPCIÓN POR LOS POBRES ES OPCIÓN POR LA JUSTICIA, Y NO ES PREFERENCIAL 
hace ni puede hacer una "opción preferencial por la justicia"7 : sino que opta por ella posicionándose radicalmente contra la injusticia y asumiendo de una manera total la causa de los injusticiados.

Esta opción de Dios por la justicia no se fundamenta en su "gratuidad", ni es una especie de "capricho" divino que pudiese haber sido de otra manera o simplemente no haber sido, como si la sanción divina de la justicia obedeciese a un simple voluntarismo ético. ${ }^{8}$

La opción de Dios por la justicia se fundamenta en su mismo ser: Dios no puede ser de otra manera, no podría no hacer esa opción sin contradecirse y sin negar su propio ser. Dios es, "por naturaleza", opción por la justicia, y esa opción no es gratuita (sino axiológicamente inevitable), ni contingente (sino necesaria), ni arbitraria (sino fundada per se en el mismo ser de Dios), ni "preferencial" (sino alternativa, exclusiva y excluyente) (Vigil, 1991: 57ss.). ${ }^{9}$

\section{Tercera tesis: La opción por los pobres es opción por los "injusticiados"}

El concepto "pobres", como parte de la expresión "opción por los pobres", ha causado cierta confusión. En efecto, si la opción es "por los pobres", explicablemente sobreviene la tentación de situar en la "pobreza" el fundamento de tal opción, ya sea identificando falsamente pobreza con santidad (lo cual se obvió desde el principio), o reelaborando metafóricamente el concepto de "pobreza" en diferentes direcciones ${ }^{10}$, o derivándolo hacia cual-

7. Quien opta "preferencialmente" por la justicia, opta también, aunque sea menos preferencialmente, por la injusticia. En el dilema de justicia e injusticia no hay "simples preferencias" posibles: la opción está ante alternativas de una disyuntiva excluyente.

8. Recordemos la posición teológica medieval (el "voluntarismo ético") de quienes sostenían que el orden moral actual no era necesario sino contingente, y que obedecía a una voluntad positiva y gratuita (arbitraria) de Dios. El orden moral -sostenía esta doctrina- hubiera podido ser otro, incluso el contrario al actual, si Dios así lo hubiese querido en un inescrutable designio arcano de su voluntad.

9. Vigil, J.M., Opción por los pobres, ipreferencial y no excluyente?, en Sobre la opción por los pobres, Sal Térrea, Santander, 1991, pp. 57ss. Ediciones también en Nicaragua, Editorial Nicarao, 1991; Chile, Rehue, 1992; Colombia, Paulinas, 1994; Ecuador, Abya Yala, 1998; Italia, Citadella, 1992; Brasil, Paulinas, 1992.

10. Como cuando se argumentaba que los ricos eran los verdaderos pobres (pobres en riquezas espirituales, de las que los pobres materiales eran muy ricos)... Se llegó a verdaderos juegos de palabras o malabarismos conceptuales para no entender lo obvio. Casaldáliga dió testimonio poético de ello en sus Bienaventuranzas de la 
quiera de los grupos que en el Antiguo Testamento parecen ser objeto de una "preferencia" de parte de Dios (los "débiles y pequeños"...), o por otros muchos caminos. ${ }^{11}$

Se podrán evitar estos desvíos si se trae a luz el papel teológico que el concepto de "pobres" juega concretamente en la expresión "opción por los pobres". Teológicamente hablando, "pobres" funge ahí exactamente como "injusticiados". Porque Dios no opta por los pobres en cuanto pobres (materiales, económicos), sino en cuanto "injusticiados". La pobreza económica no es por sí misma una categoría teológica, sino la injusticia que puede darse en esa pobreza económica. Teológicamente considerada, la "opción por los pobres" es en realidad "opción por los injusticiados". ${ }^{12}$ Si se llama opción "por los pobres", ello se debe a que, quoad nos, los pobres (económicos) son el primer analogado de la injusticia y su expresión máxima o por antonomasia.

Hablando con precisión teológica, los destinatarios de esta opción por los pobres no pueden ser identificados sin más como los "pobres económicos" por sí mismos, ni los "pobres que son buenos", ni los que son "pobres en algún sentido", o los que tienen "espíritu de pobres"... (delimitaciones todas ellas muy lábiles, resbaladizas, a causa de los juegos metafóricos del lenguaje), sino los "injusticiados", sean pobres económicos o no, metafóricos o no.

Por el contrario: los "pequeños y los débiles", o sea, todos aquellos cuya "pobreza" no puede ser medida en términos de injusticia ${ }^{13}$, no deben ser identificados como destinatarios netos de la opción por los pobres, sino por extensión metafórica. Pueden ser objeto de una "ternura especial" y gratuita por parte de Dios y nuestra, pero este sentimiento y esta actitud no deben ser confundidas con la opción por los pobres.

conciliación pastoral: Bienaventurados los ricos, / porque son pobres de espíritu. / Bienaventurados los pobres, / porque son ricos en Gracia. / Bienaventurados los ricos y los pobres, / porque unos y otros son pobres y ricos. / Bienaventurados todos los humanos, / porque allá en Adán, son todos hermanos. / Bienaventurados, en fin, / los bienaventurados / que, pensando así, / viven tranquilos... / porque de ellos es el reino del limbo.

11. Pobreza de espíritu, pobres de Yavé, virtud de la pobreza, anawin, infancia espiritual...

12. "Opción por los injusticiados" es una expresión precisa, que escapa a la posibilidad de ser mistificada o metaforizada.

13. Como es el caso de las pobrezas "naturales", no históricas, sin culpa de nadie.

LA OPCIÓN POR LOS POBRES ES OPCIÓN POR LA JUSTICIA, Y NO ES PREFERENCIAL 
Toda problemática humana que sea convertible en injusticia -aunque no tenga que ver con la "pobreza" en sentido literal o económico- es objeto de la opción por los pobres (porque ésta es opción por la justicia). Así, la discriminación étnica, de género, cultural, como formas de injusticia que son, y aunque no se den junto con situaciones de pobreza económica, son objeto de la opción por los pobres. No lo son por ser formas de pobreza -que no lo son-, sino por ser formas de injusticia.

La opción por la cultura despreciada, por la raza marginada, por el género oprimido, no son opciones diferentes de la opción por los pobres, sino concreciones diversas de la única "opción por los injusticiados", a la que llamamos opción por los pobres.

\section{Cuarta tesis: La esencia teológico-sistemática de la opción por los pobres y su fundamento es la opción de Dios por la justicia}

Teológicamente hablando, en sentido dogmático-sistemático, la verdadera naturaleza de la opción por los pobres, es la opción de Dios por la justicia. La "radiografía teológica" de la opción por los pobres, el fundamento sobre el que se sostiene, lo que en realidad la constituye, es la opción de Dios por la justicia. $^{14}$

Si se ignora su relación con la justicia y se la emparenta con una simple "voluntad gratuita" de Dios, la opción por los pobres se extravía por caminos que la desvirtúan, la mixtifican y desnaturalizan, acabando por convertirla en un simple "amor preferencial", o una opción opcional, facultativa, gratuita, arbitraria, contingente, desvinculada de la justicia, reducida a "caridad" o beneficencia.

La opción por la justicia de Dios es mayor que -y anterior a- lo que la teología de la liberación latinoamericana captó y expresó como opción por los pobres. La opción por los pobres no es sino una captación -importante pero no agotadora de la totalidad- de esa opción de Dios por la justicia. La opción por los pobres es una forma nuestra de percibir, de expresar y de asumir esa opción de Dios por la justicia.

14. “La opción por los pobres concretiza el 'amor' de Dios -su última definición- como justicia que sale en favor del oprimido." (Sobrino, 1983: 890) 
"Opción por los pobres" es un nombre pastoral, histórico, escogido en función de su inteligencia inmediata. Pero, teológico-sistemáticamente considerada, es decir, atendiendo a su esencia teológica más profunda, la opción por los pobres "es" opción por la justicia y el nombre que mejor expresaría su naturaleza teológica sería el de "opción por los injusticiados". ${ }^{15}$ No abogamos por un cambio de nombre; simplemente llamamos la atención sobre el hecho de que el nombre no corresponde a lo que sería una "definición esencial"16 de la opción por los pobres.

\section{Quinta tesis: Como opción por la justicia que es, la opción por los pobres no es preferencial, sino disyuntiva y excluyente. Por el contrario, la opción preferencial por los pobres es simplemente una prioridad y ni siquiera es una "opción"}

La opción por los pobres es una toma de posición espiritual, integralmente humana, y por tanto también social y política, en favor de los pobres en el marco del conflicto social histórico, y por eso es una opción disyuntiva y excluyente (Vigil, 1991: 57ss.). ${ }^{17}$

La "opción (no preferencial) por los pobres" (opción por los pobres ) pertenece al campo de la justicia y se fundamenta en la opción misma de Dios por la justicia. Por el contrario, la "opción preferencial por los pobres" pertenece a ámbito de la caridad ${ }^{18}$ y puede ponerse en relación con la gratuidad de Dios. La opción por los pobres no tiene aplicabilidad ante las pobrezas naturales. La opción preferencial por los pobres, por el contrario, sólo tiene validez para las pobrezas naturales.

15. Por eso los nuevos sujetos no necesitan una "opción" por la mujer, el/la indígena" o afro, sino que la misma opción por los "injusticiados" incluye a todos/as ellos/as.

16. "Definición esencial", al decir de la lógica clásica, es aquella que no sólo discrimina adecuadamente su objeto, sino que lo hace en referencia a su esencia (y no, por ejemplo, en base a un "propio" o a un conjunto de accidentes suficientemente discriminante).

17. "Pobres y empobrecedores, oprimidos y opresores, Reino y antirreino, Dios de la vida e ídolos de muerte... ambos tipos de realidades están en conflicto y en lucha, y la opción por uno es opción contra otro" (Sobrino, 1993: 891).

18. O de las clásicamente llamadas "obras de misericordia"; por ello, la opción preferencial por los pobres puede ser llamada con propiedad, efectivamente, "amor preferencial por los pobres". Eso es lo que es. La opción por los pobres es otra cosa.

LA OPCIÓN POR LOS POBRES ES OPCIÓN POR LA JUSTICIA, Y NO ES PREFERENCIAL 
La opción por los pobres ve la pobreza como una injusticia a erradicar mediante el amor político y trasformador, mediante una praxis social, como acto de justicia. La opción preferencial por los pobres, por su parte, ve la pobreza como algo lamentable pero tal vez natural, como algo que simplemente hay que compensar con actos de generosidad gratuita, asistencialmente.

La "preferencialización" de la opción por los pobres, o sea, el desplazamiento o la sustitución de la opción por los pobres mediante la opción preferencial por los pobres, funge como un ocultamiento de las coordenadas de la justicia para mirar la realidad sólo desde la perspectiva de la beneficencia o el asistencialismo; o como la reducción del amor cristiano a una misericordia privatizada y una solidaridad espiritualizada. Un cristianismo con opción preferencial por los pobres pero sin opción por los pobres es funcional a cualquier sistema injusto. La oposición a la opción por los pobres -y en general, a la teología y espiritualidad de la liberación en cuyo seno aquella nació- ha fungido como el principal objetivo de quienes han intentado revertir la renovación posconciliar de la teología y la espiritualidad latinoamericanas con Medellín y Puebla, y como la vuelta a una Iglesia que legitima del sistema capitalista y neoliberal que también hostilizó frontalmente a la Iglesia de la liberación latinoamericana y a sus innumerables mártires.

Aplicado a la opción por los pobres, el adjetivo "preferencial", al implicar una relación de simple prioridad entre términos exentos de disyuntiva o mutua exclusión, desnaturaliza la opción por los pobres, convirtiéndola en una simple prioridad o preferencia de orden y al negar la posibilidad de una opción radical por uno de los términos sometidos a relación de preferencia. Por eso, rigurosamente hablando, la opción preferencial por los pobres no es opción por los pobres, sino, como han expresado sus teóricos, un simple "amor preferencial" o una "forma especial de primacía en el ejercicio de la caridad cristiana". Es una prioridad, y ni siquiera es una "opción", en el sentido fuerte de la palabra. ${ }^{19}$ La adición del adjetivo "preferencial" ha fungido en muchos casos como "caballo de Troya" que ha introducido en la opción por los pobres el germen de su misma desnaturalización. Afortunadamente, son muchos los que han adoptado sólo externamente el uso del adjetivo, por

19. El acto por el que una persona hace su opción por los pobres o elige su lugar social participa del carácter antropológico existencial que tiene la llamada "opción fundamental". 
las presiones del entorno, sin abandonar interiormente la comprensión y la vivencia radical de lo que es la genuina naturaleza de la opción por los pobres, no preferencial, exclusiva y excluyente.

\section{APLICACIONES Y COROLARIOS}

\section{Opción por los pobres: trascendental al nivel de la norma normans}

En su sentido teológico-sistemático (antes pues, o más allá de su aplicación concreta a mediaciones no teológicas, y bien distinguida de éstas), la opción por los pobres es un trascendental que sobrepasa y atraviesa las dimensiones teológicas y pertenece esencialmente a la misma imagen del Dios bíblico y cristiano. Nuestro Dios "es" -por lo más nuclear de la revelación bíblica ${ }^{20}$ y cristiana, y por sí mismo- opción por la justicia ${ }^{21}$, con absoluta precedencia y con total independencia de toda escuela teológica o de cualquier carisma o espiritualidad en la que nos movamos. En esta calidad, la opción por los pobres no es susceptible de ser normada por dimensiones subalternas ${ }^{22}$ (se sitúa en el nivel máximo de la norma normans); y, percibida en conciencia, ha de ser obedecida como en obediencia a Dios mismo, con disposición de espíritu para la prueba del amor mayor.

En este mismo sentido, la opción por los pobres no es una "teoría" de la teología latinoamericana de la liberación, sino una dimensión trascendental del cristianismo, dimensión que esa teología ha tenido el mérito de redescubrir - para el cristianismo universal- como vinculada a la esencia misma de Dios. Este re-descubrimiento es efectivamente "el mayor acontecimiento de la historia del cristianismo en los últimos siglos" ${ }^{23}$, y marca un antes y un

20. Dios no tiene favoritismos (Ro 2, 11). El Soberano de todos no hace diferencia entre las personas y no hara caso a la grandeza (Sab 6, 7). Un juicio implacable espera a los poderosos; el pequeño tiene disculpas y merece compasión, pero los poderosos serán castigados severamente. Él creó a los grandes y a los pequeños y de todos cuida por igual. Los poderosos serán examinados con más rigor. (Sab 6, 6.7b.8). Maestro, sabemos que eres justo y que no tienes acepción de personas... (Mt 22,16). El ser humano mira las apariencias, pero Yahvé mira el corazón... (1 S 16, 7).

21. "La lucha por la justicia es como otro nombre del Dios del Antiguo Testamento y del Dios de Jesús." (Velasco, 1992: 33)

22. Eclesiásticas o disciplinares por ejemplo.

LA OPCIÓN POR LOS POBRES ES OPCIÓN POR LA JUSTICIA, Y NO ES PREFERENCIAL 
después, imborrable y sin retorno, para aquéllos para quienes la opción por los pobres ha sido una experiencia espiritual de conversión al Dios de los pobres. La opción por los pobres ha de ser considerada como "firme e irrevocable" y como una "nota de la verdadera Iglesia".

\section{Pobreza, riqueza e injusticia}

Respecto de la identificación de la opción por los pobres como opción por la justicia, podemos hacer alguna prolongación en lenguaje más aplicado.

- $\quad$ Si la pobreza de una persona o grupo es debida a que ha sido víctima de la injusticia ${ }^{24}$-y en esa medida- Dios está de parte de ese pobre, contra su pobreza, y contra los causantes de esa pobreza-injusticia. Y lo está, necesariamente, de un modo "excluyente" de la injusticia de los injustos, y no simplemente con una "opción preferencial no excluyente".

Si se trata de alguna "pobreza" que no tenga que ver con la justicia ("pobrezas naturales", de raza, de género, de cultura...) Dios no hace discriminaciones a ese respecto, ni "prefiere" en ese campo a nadie. Dios no prefiere ni posterga a ninguna raza o género o cultura por sí mismos.

- $\quad$ Si la riqueza de una persona o grupo implica injusticia -y en esa medida-, Dios está decididamente contra esa riqueza, contra el modo de vida que la genera, porque él está de parte de los que sufren las consecuencias de la injusticia y en contra de los que la causan. Y está en esa actitud de un modo necesario y de un modo que excluye esa injusticia, y no con una opción sólo "preferencial hacia el pobre" pero no radicalmente excluyente del "modo de vida del rico"25 que produce esa injusticia.

23. “Personalmente opino que con la opción preferencial por los pobres se ha producido la gran y necesaria revolución copernicana en el seno de la Iglesia, cuyo significado desborda el contexto eclesial latinoamericano concierne a la Iglesia universal. Sinceramente, creo que esta opción significa la más importante trasformación teológicopastoral acaecida desde la Reforma protestante del siglo XVI". (Lois, 1986: 193).

24. Es lo que se quería decir con la preferencia del adjetivo dinámico "empobrecidos" (como dinámico es también el concepto de "injusticiado") sobre el nombre estático de "pobres".

25. Por "modo de vida del rico" entendemos todo lo que implica el rico -excepto su persona misma-: su estilo de vida, su papel social, la causa a la que objetivamente sirve, su lujo, su explotación de los pobres, su participación en el sistema que los explota...

JOSÉ MARÍA VIGIL 
Si hay alguna riqueza que no tiene que ver con la injusticia (cualidades psicológicas, género, dones corporales y/o espirituales, azar...) Dios no hace ahí discriminaciones: ni prefiere ni posterga a nadie.

Dicho de otra manera:

- $\quad$ Si en la realidad social sólo vemos personas blancas o negras, pequeñas o grandes, fuertes o débiles, significantes o insignificantes (es decir, diferencias simplemente naturales, no dialécticas, no conflictivas, no políti$\left.\operatorname{cas}^{26}\right)$, sólo podremos Ilegar a pensar que Dios tiene alguna "preferencia", concretamente hacia los pequeños, los débiles, los insignificantes, pero no una "opción" o toma de partido excluyente (porque esto sería injusto de parte de Dios). El fundamento de esa "preferencia", efectivamente, podría ser la "gratuidad" de Dios, y la acción que postularía de parte nuestra sería la beneficencia, la limosna o el asistencialismo. Este es el caso de la opción preferencial por los pobres.

- $\quad$ Si en la realidad social somos capaces de ver personas empobrecidas por otras enriquecidas ${ }^{27}$, razas dominantes frente a culturas dominadas, un género opresor frente a otro oprimido, podemos llegar a la captación de la evidencia de que Dios ahí no puede tener simples "preferencias", sino que toma verdaderas opciones "opciones" y "se pone de parte de" los injusticiados y "en contra" de la injusticia, y esa opción de Dios es radical, disyuntiva y excluyente de la contraria. Su fundamento teológico no es la gratuidad de Dios, sino su justicia, y, consecuentemente, conlleva hacia nosotros la exigencia de una "opción" semejante: radical, disyuntiva, exclusiva, con implicación de opción por un lugar social, y con un compromiso de praxis de trasformación histórica. Es el caso de la opción por los pobres.

\section{El concepto de justicia como mediación}

Lógicamente, los principios teológicos están obligados a pasar necesariamente por el filtro ulterior de diversas mediaciones filosóficas, sociológicas y hasta políticas, a la hora de ser puestos en práctica sobre la arena de la realidad.

26. Ya sea porque así son efectivamente o porque así las queremos mirar.

27. Adviértase el carácter dinámico, activo y procesual de los adjetivos.

LA OPCIÓN POR LOS POBRES ES OPCIÓN POR LA JUSTICIA, Y NO ES PREFERENCIAL 
Por ejemplo: el concepto mismo de "justicia", con todas sus implicaciones filosóficas, sociológicas, políticas y hasta culturales, será una mediación especialmente influyente en el campo de esta "opción por los pobres". Hay un concepto capitalista de justicia, hay otro socialista, hay otro neoliberal, hay otro imperialista... Las personas estamos influenciadas por uno u otro según el "lugar social" que ocupamos, o por el que optamos. Para quien la justicia sea simplemente "dar a cada uno lo suyo", un mundo de extremas desigualdades puede parecer justo si -por ejemplo- sólo valora la actual legalidad de la propiedad privada absolutizada. No se lo parecería a ninguno de los padres de la Iglesia, ni a quien haga suyo el concepto de justicia social distributiva y democrática de la doctrina social de la Iglesia, porque estas personas operan con un concepto de justicia muy diferente.

En este sentido, a pesar de referirnos teóricamente a un mismo Dios, y a pesar de aceptar tal vez como evidente su opción por la justicia, la visión de la voluntad de Dios sobre el mundo puede ser diversa o hasta contraria en unos cristianos y en otros. ¿Dónde está el origen de esa discrepancia?

Podría no estar en el concepto mismo que tengamos de Dios ni de su proyecto o voluntad, sino en el concepto de justicia con el que construimos nuestros juicios morales. El origen puede estar en el juicio moral que, desde el concepto de justicia de cada quien, hacemos sobre la pobreza y la riqueza y sobre los mecanismos sociales o estructuras que las generan o producen, sea que los juzguemos como naturales o como históricos, como fatales o como corregibles, como casuales o como causadas, culpables o inculpables, estructurales o coyunturales, producto esencial del sistema perverso o subproducto accidental negativo de un sistema social no necesariamente negativo...). Así, por ejemplo:

- $\quad$ a quien la actual división tan desigual de la riqueza en el mundo (la famosa "copa de champán" de los informes del PNUD) le parezca "natural", pensará también -con buena lógica- que Dios no se pronuncia sobre ella, o que solamente nos exhorta a la limosna, a la beneficencia, a la gratuidad generosa... para paliar esas lamentables diferencias "naturales"...

- a quien, por el contrario, le parezca que tal división del mundo es injusta y pecaminosa, le parecerá -también con buena lógica- que Dios está irritado con ella y que desea ardientemente que sea abolida, y que quiere que le ayudemos a combatir ese injusto desorden con un compromiso radical por la justicia; 
- $\quad$ a quien piense que esa situación del mundo es el mayor drama de la humanidad actual, le parecerá también que su superación urgente expresa la mayor y más apremiante voluntad de Dios;

- a quien considere que el neoliberalismo es inocente, o que es "el menos malo de los sistemas", le parecerá que Dios quiere que lo apoyemos, o incluso que lo "mejoremos" en algunas de sus "deficiencias accidentales".

- $\quad$ a quien, por el contrario, le parezca que el neoliberalismo es injusto, o incluso la mayor injusticia, la más estructural, le parecerá que Dios quiere que combatamos esta estructura de pecado lo más denodadamente posible.

Según esto, parecería claro que el problema teológico se enruta hacia la discusión y el análisis de las mediaciones, y que las discrepancias se situarían no en el nivel propiamente teológico de los principios, sino en el nivel prudencial de las mediaciones. Sin embargo, esto es sólo la mitad de la verdad, porque nuestro concepto de justicia forma parte de nuestra elección de Dios. "Dime qué entiendes por justicia, y te diré cuál es tu Dios". Dime en qué justicia crees y te diré a qué Dios adoras.

Solemos pensar que nuestro concepto de justicia nos viene del Dios creído, pero también lo contrario es cierto: sólo creemos en el Dios que cabe en nuestro concepto de justicia. ${ }^{28}$ La opción más fundamental ${ }^{29}$ de nuestra vida puede ser aquella por la que optamos por un concepto u otro de justicia, justicia que es a la vez nuestra utopía para el mundo. Nuestra imagen de Dios es hija de la opción por la que elegimos nuestro concepto de justicia y su correspondiente utopía para el mundo. Y viceversa: muchos no Ilegan a asumir un concepto utópico de justicia porque previamente han hecho la opción por el Dios del egoísmo y de sus riquezas.

La opción por los pobres es pues a la vez una opción por Dios (de los pobres) y una opción por la justicia utópica (del Reino). La "opción por los ricos" es a la vez una renuncia al Dios de los pobres y una opción por una justicia resignada al egoísmo. La opción por los pobres o por los ricos, la

28. Sobrino llega a decir que "la opción por los pobres es necesaria para comprender la revelación" (Sobrino, 1993: 885).

29. Juan Luis Segundo dice que la opción por los pobres funge como una "fe antropológica", como una "apuesta", algo muy cercano a la "opción fundamental". Cfr. La opción por los pobres como clave hermenéutica para entender el Evangelio, en la Revista Electrónica Latinoamericana de Teología, RELaT, http://servicioskoinonia.org/relat/118.htm

LA OPCIÓN POR LOS POBRES ES OPCIÓN POR LA JUSTICIA, Y NO ES PREFERENCIAL 
justicia utópica y la justicia resignada, y el Dios de los pobres o su rechazo, están mutuamente implicados en un círculo hermenéutico. La obediencia a Dios nos la jugamos no en una relación directa hacia Dios, sino en la elección de un ideal de justicia utópica o de una justicia resignada. ${ }^{30}$ Principios y mediaciones están más mutuamente implicados que lo que parecería. Dios es justo, y la justicia es divina. La opción por los pobres es a la vez un acto de fe en el Dios de los pobres y una opción ética y humanizante por la justicia (la de los pobres y la de Dios simultáneamente). Por su parte, la opción por el egoísmo es a la vez una injusticia y un rechazo de(l) Dios (de los pobres). Y volvemos al principio: Dios y la opción por los pobres no se pueden separar, porque la opción por los pobres se fundamenta en Dios mismo, en su justicia. La gratuidad de Dios es otro tema.

\section{Bibliografía}

Boff, C., “¿Quiénes son hoy los pobres, y por qué?" en PIxley, J. y Boff, C., Opción por los pobres, Paulinas, Madrid, 1986.

Gutiérrez, Gustavo, “El Dios de la Vida”, en Christus, 47, México, 1982.

Gutiérrez, Gustavo, La fuerza histórica de los pobres, Lima, 1980.

GutiérRez, Gustavo, "Pobres y opción fundamental", en Mysterium Liberationis, UCA Editores, San Salvador, 1991.

GutiérRez, Gustavo, “Una teología de la liberación en el contexto del tercer milenio", en VARIOS, El futuro de la reflexión teológica en América Latina, CELAM, Bogotá, 1996.

LoIs, JuLıo, Teología de la liberación: opción por los pobres, IEPALA, Madrid, 1986.

Revista Electrónica latinoamericana de Teología, la opción por los pobres como clave hermenéutica para entender el Evangelio, en http://servicios koinonia.org/relat/118.htm

30. Casaldáliga expresaba el conflicto entre los dos dioses y las dos justicias en su poema "Equívocos": Donde tú dices ley / yo digo Dios. / Donde tú dices paz, justicia, amor, / ¡yo digo Dios! / Donde tú dices Dios, /iyo digo libertad, / justicia, / amor! 
Sobrino, Jon, "Opción por los pobres" en Floristán-Tamayo, Conceptos fundamentales del cristianismo, Trotta, Madrid, 1993.

Velasco, Rufino, La Iglesia de Jesús, Verbo Divino, Estella, 1992.

VIGIL, J.M., “Opción por los pobres: ¿preferencial y no excluyente?, en Vigil, J.M., (org), Sobre la opción por los pobres, Sal Terrae, Santander, 1991. 